\section{HTM 01-05: STAY IN CONTROL WITH COLOUR-CODED LABELS}

Positive I.D. Labelling has created a new system of colour-coded labelling to help dental practices meet the HTM 01-05 legislation. Dental practices using non-vacuum sterilisers (type $\mathrm{N}$ ) must have a system in place to ensure that storage of sterilised instruments does not exceed 21 days.

The new labels state the date dental instruments were sterilised and the date that they need to be used by. They are also colourcoded into a four weekly cycle. This enables the dental team to see, at a glance, which instruments are approaching their 'use by' dates, so they can rotate them accordingly.

The labels are attached to sealed packaging, once items have been sterilised, using a stateof-the-art labelling gun, which prints and sticks labels in one smooth movement.

The labels can be personalised and come in a range of sizes and formats.

The labelling gun and 22,000 each of the four-colour labels are available to dental practices for a special price of $£ 249+V A T$. www.pid-labelling.co.uk/pid_pages/dentist.php Reader response number 55

\section{MAKE AN IMPRESSION ONTHE HOOF}

Grahame Gardner Ltd urge dental professionals to take a walk on the wild side with their selection of bold unisex clogs. Alongside classic healthcare clogs and shoes, the new styles come in a variety of eye-catching prints - guaranteed to make an impression!

The 0497 is a practical shoe developed with comfort in mind with a shock absorbing heel and a slip resistant sole. Stocked patterns include zebra, tiger and Dalmatian prints.

All of the styles have been selected for their suitability for individuals who spend a lot of their working day on their feet

Reader response number 57

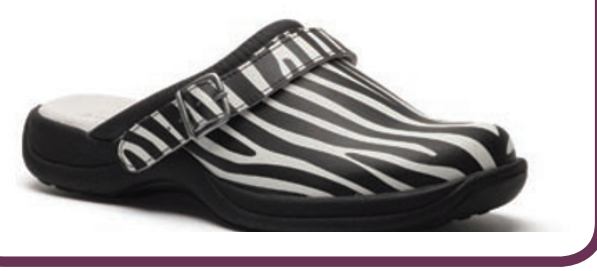

\section{ANTIBACTERIAL UPHOLSTERY}

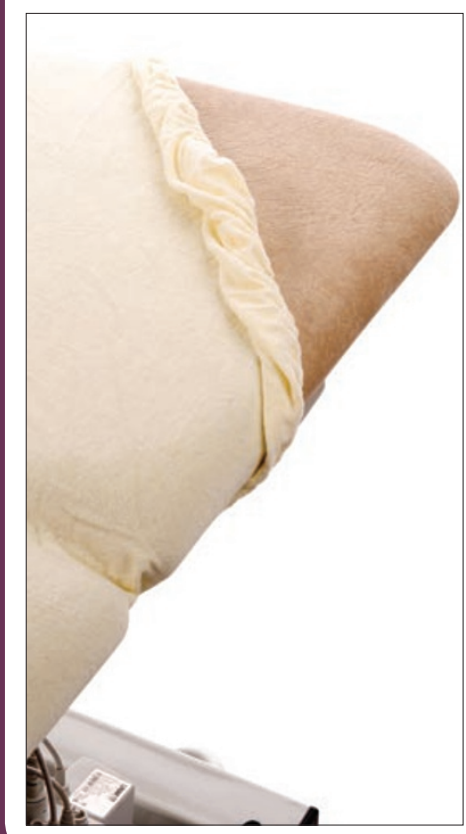

All Plinth 2000 couch coverings are vinyl, washable, stain resistant and capable of withstanding disinfection with a chlorine-based product.

Most of its standard upholstery grades incorporate a patented antibacterial additive, which provides long-lasting effectiveness against MRSA, C.Diff, E.coli and other harmful bacteria and is also resistant to mould and odours.

One area of particular risk is upholstery damage, through cuts, tears or poor cleaning technique. Plinth recommends regular inspection and servicing, with the option of replacing damaged vinyl as soon as any problem occurs. Plinth 2000 has designed its couch upholstery for ease and speed of replacement. It also offers the option of upgrading older models to antibacterial upholstery. Plinth 2000 accessories include paper roll holders, tailor-made plinth covers and foot controls for electric height adjustment.

Reader response number 56

\title{
INSTRUMENT DECONTAMINATION ONLINE
}

Eastwood Park Training is launching a unique online dental instrument decontamination training course.

This new programme will assist dental practices in complying with the HTM 01-05 regulations, as well as gain verifiable $\mathrm{CPD}$.

This flexible online course is ideal for NHS and private dental practices and hospitals as learning can take place at work or at home, reducing time away from the surgery and enabling individuals to work at their own pace.

The course is modular allowing staff to learn and develop all of the regulatory requirements relating to HTM 01-05 and includes two hours of verifiable CPD. Reader response number 58

\section{GREAT VALUE LIGHTWEIGHT INSTRUMENTS}

UnoDent, the high quality range of dental supplies available exclusively from The Dental Directory, is delighted to introduce the latest development in their instrument family, the Resin Handle.

Specially sourced for dental hygienists, these lightweight instruments weigh just $11 \mathrm{~g}$ each and their ergonomic design means you can use them for longer. Colour coded for easy identification and fully autoclavable, being manufactured from A40A grade stainless steel, the UnoDent Resin Handled Instruments are also great value for money from just $£ 10.62$ each.

If you buy any three UnoDent Resin Handled Instruments before 31 December 2010 you will get a free pack of UnoDent Sterilisation Pouches worth $£ 7.20$ (GBS520).

Reader response number 59

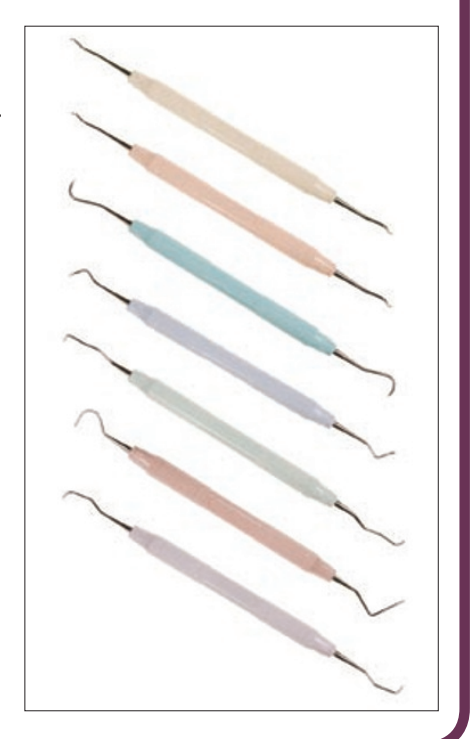

If you would like to promote your products or services direct to the dental industry through VITAL UPDATE telephone Avia or Andy on 02078434833. 